\title{
Global Research on Quality of Life of Patients with HIV/AIDS: Is It Socio-Culturally Addressed? (GAPRESEARCH)
}

\author{
Giang Thu Vu ${ }^{1}$, Bach Xuan Tran 2,3®0, Chi Linh Hoang ${ }^{4}$, Brian J. Hall ${ }^{3,5}$, Hai Thanh Phan ${ }^{6}$, \\ Giang Hai Ha ${ }^{6, *}$, Carl A. Latkin ${ }^{3}{ }^{\circ}$, Cyrus S.H. Ho ${ }^{7}$ and Roger C.M. Ho ${ }^{4,8,9}$
}

1 Center of Excellence in Evidence-Based Medicine, Nguyen Tat Thanh University, Ho Chi Minh City 700000, Vietnam; giang.coentt@gmail.com

2 Institute for Preventive Medicine and Public Health, Hanoi Medical University, Hanoi 100000, Vietnam; bach.ipmph@gmail.com

3 Bloomberg School of Public Health, Johns Hopkins University, Baltimore, MD 21205, USA; brianhall@umac.mo (B.J.H.); carl.latkin@jhu.edu (C.A.L.)

4 Center of Excellence in Behavioral Medicine, Nguyen Tat Thanh University, Ho Chi Minh City 700000, Vietnam; chi.coentt@gmail.com (C.L.H.); pcmrhcm@nus.edu.sg (R.C.M.H.)

5 Global and Community Mental Health Research Group, University of Macau, Macau 999078, China

6 Institute for Global Health Innovations, Duy Tan University, Da Nang 550000, Vietnam; haipt.ighi@gmail.com

7 Department of Psychological Medicine, National University Hospital, Singapore 119074, Singapore; cyrushosh@gmail.com

8 Department of Psychological Medicine, Yong Loo Lin School of Medicine, National University of Singapore, Singapore 119228, Singapore

9 Institute for Health Innovation and Technology (iHealthtech), National University of Singapore, Singapore 119077, Singapore

* Correspondence: giang.ighi@gmail.com; Tel.: +84-8-6954-8561

Received: 21 December 2019; Accepted: 19 March 2020; Published: 23 March 2020

\begin{abstract}
Quality of life (QOL) has been considered as an important outcome indicator in holistic care for HIV-infected people, especially as HIV/AIDS transforms from a fatal illness to a chronic condition. This study aimed to identify trends and emerging topics among research concerning the QOL of people living with HIV/AIDS (PLWHA). The analyzed data were English papers published from 1996 to 2017, searched and extracted from the Web of Science Core Collection. Collaborations between countries and the correlation between the keywords were visualized by VOSviewer while the abstracts' content was analyzed using exploratory factor analysis and Jaccard's' similarity index. There has been an increase in both the number of publications and citations. The United Nations of America leads in terms of paper volume. The cross-nation collaborations are mainly regional. Despite a rather comprehensive coverage of topics relating to QOL in PLWHA, there has evidently been a lack of studies focusing on socio-cultural factors and their impacts on the QOL of those who are HIV-infected. Further studies should consider investigating the role of socio-cultural factors, especially where long-term treatment is involved. Policy-level decisions are recommended to be made based on the consideration of cultural factors, while collaborations between developed and developing nations, in particular in HIV/AIDS-ridden countries, are strongly recommended.
\end{abstract}

Keywords: scientometrics; HIV/AIDS; bibliometric; quality of life 


\section{Introduction}

Human immunodeficiency viruses (HIV) is one of the leading causes of disability and mortality worldwide, with more than 76.1 infected people and 35.0 million deaths [1-3]. In 2017, there were 1.8 million people newly infected with HIV and Acquired immunodeficiency syndrome (AIDS), 36.9 million people living with HIV and AIDS (PLWHA), and 940,000 deaths related to life-threatening infections and cancers [4]. Hence, ensuring sufficient care and treatment, as well as treatment provision, has become a challenge for global public health systems.

Quality of life (QOL), as noted by the existing literature, has been described as an umbrella term for a variety of human needs, including the position in life, goals, standards, expectations, and concerns in the context of the culture and value systems. It manifests within patients as symptomatic, social functioning, and spirituality [5]. In terms of health promotion, health-related quality of life (HRQOL) is also considered as a priority health indicator. Since 1996, optimizing adherence to Antiretroviral Therapy (ART) has brought the chance to transform HIV—an incurable disease-into a chronic health condition [6], which in turn prolongs the life of PLWHA and improves their QOL [6]. In many settings, poor QOL is associated with a lower immune response, non-adherence, poor mental health, and greater disease severity [7-9]. Therefore, QOL attracted great attention from regulatory authorities and health providers as an important outcome to evaluate the effectiveness of HIV treatment [10-13]. People who were effectively treated with HAART, however, have been found to have a lower QOL compared with other long-term chronic illnesses [14]. Over time, the expansion of HAART coverage not only prolonged the life expectancy of PLWHA, but also boosted the innovation of new QOL instruments to adapt to the complexity of care. The previous literature has reported a high burden of comorbidities suffered by PLWHA, as well as adverse side impacts of long-term treatment on their health $[15,16]$, while a complex combination of psychological and social factors which also influence their physical, mental and social conditions, directly and indirectly, affect their QOL [17-22]. On the other hand, in recent years, the availability of early HIV diagnosis, antiretroviral (ARV) treatments and enhanced healthcare services have been found to support the improvement in the QOL of PLWHA [23].

Thus, in order to improve the quality and effectiveness of HIV/AIDS treatment and prevention programs, qualitative as well as quantitative analyses on the QOL of PLWHA are needed. In 2017, Cooper, et al. conducted a systematic review on the finding of existing reviews on QOL of the HIV/AIDS-infected population in various aspects, including the development, validation, and effectiveness of the most commonly used instruments [12]. Though informative, reviews of such kind suffer from the limitation of a narrow focus on specific questions or issues. In order to broaden the scope of research, a new approach is needed that has the ability to cover a large volume of global data on QOL in PWLHA research and allows for complex analysis to identify the research trend $[12,18,24,25]$.

Our study adopts the scientometrics approach that gathers and analyze publications on a global level, coupled with more a technical analysis approach applied to the content of papers' title and abstract to identify emerging research topics as well as the current level of international collaboration in research on the QOL of PLWHA. This study aims to supplement the current literature while uncovering research gaps, suggest directions for future studies, and act as a reference point for priority settings and strategies initiating in HIV/AIDS management.

\section{Materials and Methods}

\subsection{Study Design}

Serving as the best approach to evaluate evidence, the increase in the number of systematic reviews of QOL regarding HIV/AIDS could provide an insightful view of various aspects, including evaluating the effectiveness of instruments, clinical intervention, and HIV/AIDS programs in vulnerable populations. In addition to having a limited scope of research; such reviews also remain lack of the comparison of findings over time and overlap with information. Several researchers use bibliometrics 
with the expectation that it could fill the gap in the literature and provide the research trend using quantitative analysis. It can be seen that the bibliometric approach sometimes could not draw a full picture because the majority only present the number without a comprehensive reading of the literature [26]. In order to provide a comprehensive view of the current status of the quality of life in terms of the HIV/AIDS literature, we conducted the scientometric approach combined with content analysis.

The current study is a part of a larger project, Global Analysis for Policy in Research (GAPRESEARCH), that aims to set priorities in global health evolution and provide empirical evidence for designing effective interventions and policies [27-32]. The findings of this study, therefore, can be used as a reference point for directing investments, allocating resources, and crafting policies.

\subsection{Search Strategy}

A search for HIV/AIDS publications was performed on the Web of Science (WoS) Core Collection. This database was prioritized because it has covered all scientific publications with full cited reference indexing since 1900 and allowed downloading information with a diversity of research disciplines that far outweigh other databases such as Scopus or MEDLINE [32].

We applied a search query containing the search terms of "HIV" OR "human-immunodeficiencyvirus" OR "AIDS" OR "Acquired-Immune-Deficiency-Syndrome". Data were extracted in a unit of 500 publications from the first publication in the dataset end up in 2017. As the process was conducted in July 2018, we excluded all papers published in 2018 as the partial coverage of publications published in 2018 would not fully reflect the publication trend of the year. The selection criteria for study subjects were English peer-review articles, including original articles and reviews (see Figure A1). Any paper with anonymous or no authors would be excluded. In the next step, we continue refined relevant research by using the research term "quality of life", articles could be removed if they did not include "quality of life" in titles and abstracts. Any disagreement during the screening process could be discussed with a senior researcher.

\subsection{Summary Measures}

The retrieved data consisting mainly of publication indexes were contained the following information: Title; years of publication; the total number of papers; citations up to 2017; usages/number of downloads; keywords (authors' keywords); authors' affiliations; most prolific countries and collaborations. In order to describe the change of publication over time, we calculated several fundamental domains including the speed of publication (total number of papers), the level of reader attention (mean cited rate per year), the level of short-term and long-term interest (mean usage rate last 6 months/5 years). We also illustrated the major topic clusters and landscapes of QOL in the field of HIV/AIDS by calculating the frequency of co-occurrence of keywords and synthesized from abstract's content.

\subsection{Data Analysis}

The extracted data were sorted by Macro in Microsoft Excel to calculate the indexes. The connection among countries by sharing co-authorships' data (we applied full counting for papers sharing by more than one country), networks of co-occurrence authors' keywords, and clusters of topic groups were visualized by VOSviewer (version 1.6.11, Center for Science and Technology, Leiden University, the Netherlands). The cluster topics of QO were then identified from the frequency of keywords and named by expert opinions.

The exploratory factor analysis (EFA) and Jaccard's similarity index were performed using STATA software version 15.0. This index was defined as the magnitude of the intersection divided by the magnitude of the union of two sets of co-occurring terms; thus, multi-dimensional scaling could be used to adjust a point for a topic category, the distance between items and color presented the partnership of certain key terms. To measure the likelihood of research trends (e.g., emerging research 
domains and landscapes), we utilized exploratory factor analysis (EFA), which allows us to test the variance in the domains and landscape appearing from the abstract's contents. The summary of the technique used for analyzing is described in Table A1.

\section{Results}

Table 1 shows an expansion in the volume of publications on QOL among HIV/AIDS populations. The period between 2007 and 2017 saw the number of papers grow from 114 to 234. In particular, the total citation (from the year published up to 2017) has also risen remarkably in 2005 and 2013.

Table 1. General indicators of publications

\begin{tabular}{|c|c|c|c|c|c|c|c|}
\hline $\begin{array}{c}\text { Year } \\
\text { Published }\end{array}$ & $\begin{array}{c}\text { Total } \\
\text { Number } \\
\text { of Papers }\end{array}$ & $\begin{array}{c}\text { Total } \\
\text { Citations }\end{array}$ & $\begin{array}{c}\text { Mean Cite } \\
\text { Rate per } \\
\text { Year }^{1}\end{array}$ & $\begin{array}{l}\text { Total Usage* } \\
\text { Last } 6 \text { Months }\end{array}$ & $\begin{array}{l}\text { Total Usage* } \\
\text { Last } 5 \text { Years }\end{array}$ & $\begin{array}{c}\text { Mean Use } \\
\text { Rate Last } 6 \\
\text { Months }^{2}\end{array}$ & $\begin{array}{c}\text { Mean Use } \\
\text { Rate Last } \\
5 \text { Years }{ }^{3}\end{array}$ \\
\hline 2017 & 234 & 11,965 & 51.1 & 356 & 1,151 & 1.5 & 1.0 \\
\hline 2016 & 215 & 11,221 & 26.1 & 211 & 1,619 & 1.0 & 1.5 \\
\hline 2015 & 218 & 10,985 & 16.8 & 174 & 1,972 & 0.8 & 1.8 \\
\hline 2014 & 211 & 9,638 & 11.4 & 107 & 1,891 & 0.5 & 1.8 \\
\hline 2013 & 213 & 9,866 & 9.3 & 96 & 2,286 & 0.5 & 2.1 \\
\hline 2012 & 185 & 8,773 & 7.9 & 52 & 1,692 & 0.3 & 1.8 \\
\hline 2011 & 169 & 8,476 & 7.2 & 65 & 1,315 & 0.4 & 1.6 \\
\hline 2010 & 167 & 7,462 & 5.6 & 46 & 1,160 & 0.3 & 1.4 \\
\hline 2009 & 140 & 6,445 & 5.1 & 62 & 908 & 0.4 & 1.3 \\
\hline 2008 & 122 & 5,468 & 4.5 & 53 & 818 & 0.4 & 1.3 \\
\hline 2007 & 114 & 5,639 & 4.5 & 33 & 622 & 0.3 & 1.1 \\
\hline 2006 & 96 & 4,588 & 4.0 & 41 & 606 & 0.4 & 1.3 \\
\hline 2005 & 112 & 5,265 & 3.6 & 61 & 767 & 0.5 & 1.4 \\
\hline 2004 & 80 & 3,746 & 3.3 & 36 & 414 & 0.4 & 1.0 \\
\hline 2003 & 73 & 3,012 & 2.8 & 25 & 374 & 0.3 & 1.0 \\
\hline 2002 & 58 & 2,579 & 2.8 & 10 & 226 & 0.2 & 0.8 \\
\hline 2001 & 51 & 2,163 & 2.5 & 11 & 264 & 0.2 & 1.0 \\
\hline 2000 & 66 & 2,759 & 2.3 & 11 & 309 & 0.2 & 0.9 \\
\hline 1999 & 49 & 2,291 & 2.5 & 13 & 212 & 0.3 & 0.9 \\
\hline 1998 & 56 & 2,385 & 2.1 & 16 & 214 & 0.3 & 0.8 \\
\hline 1997 & 39 & 1,708 & 2.1 & 7 & 128 & 0.2 & 0.7 \\
\hline 1996 & 44 & 1,455 & 1.5 & 11 & 169 & 0.3 & 0.8 \\
\hline
\end{tabular}

* Usage: downloaded time; ${ }^{1}$ Mean cited rate per year = Total citations/(Total citations $\times(2018$-that year) $) ;{ }^{2}$ Mean usage rate last 6 months $=$ Total usage last 6 months/Total number of papers; ${ }^{3}$ Mean use rate last 5 years $=$ total usage last 5 years/(total number of papers $\times 5$ ).

Table 2 indicates the frequency of countries by counting such study settings in the mentioned abstracts. In the top 10, except countries with the highest HIV prevalence, such as South Africa, the number of studies were mostly produced in upper-middle-income and high-income countries (United States, Brazil, China, Canada, Thailand, England, Australia) [33]. The low and middle-income countries such as Botswana, Zambia, Lesotho, Swaziland had below 10 papers, even though these countries have been reported as having the highest rate of HIV/AIDS [34].

Figure 1 displays the global network between 102 countries having co-authorships of selected papers. These countries have been classified into 10 clusters of at least five countries, depending on their level of international collaboration.

Cluster 1 (red) refers to the network of countries in the two regions: South-East Asia and the Western Pacific. Cluster 2 (purple) indicates the link of the USA with European countries and Saudi Arabia. Cluster 3 (blue) illustrates international collaborations between the Americas, South Africa, and some countries in Asia. Cluster 4 (brown and green) demonstrates the co-authorship between countries within Southeast Africa. In addition, they have an additional link with England. The European countries tend to associate with each other by geographical areas, such as orange, pink, light blue, and yellow (French West Africa). 
Table 2. A number of papers by countries as study settings.

\begin{tabular}{|c|c|c|c|c|c|c|c|}
\hline No. & Country Settings & Frequency & $\%$ & No. & Country Settings & Frequency & $\%$ \\
\hline 1 & United States & 271 & $21.1 \%$ & 31 & Sweden & 8 & $0.6 \%$ \\
\hline 2 & South Africa & 108 & $8.4 \%$ & 32 & Zambia & 8 & $0.6 \%$ \\
\hline 3 & India & 74 & $5.8 \%$ & 33 & Cambodia & 7 & $0.5 \%$ \\
\hline 4 & Brazil & 60 & $4.7 \%$ & 34 & Ghana & 7 & $0.5 \%$ \\
\hline 5 & China & 60 & $4.7 \%$ & 35 & Lesotho & 7 & $0.5 \%$ \\
\hline 6 & Uganda & 52 & $4.0 \%$ & 36 & Netherlands & 7 & $0.5 \%$ \\
\hline 7 & Canada & 42 & $3.3 \%$ & 37 & Swaziland & 7 & $0.5 \%$ \\
\hline 8 & Thailand & 32 & $2.5 \%$ & 38 & Switzerland & 7 & $0.5 \%$ \\
\hline 9 & United Kingdom & 30 & $2.3 \%$ & 39 & Hong Kong & 6 & $0.5 \%$ \\
\hline 10 & Australia & 29 & $2.3 \%$ & 40 & Jamaica & 6 & $0.5 \%$ \\
\hline 11 & Ethiopia & 27 & $2.1 \%$ & 41 & Japan & 6 & $0.5 \%$ \\
\hline 12 & Niger & 25 & $1.9 \%$ & 42 & Nepal & 6 & $0.5 \%$ \\
\hline 13 & Nigeria & 25 & $1.9 \%$ & 43 & Germany & 5 & $0.4 \%$ \\
\hline 14 & Malawi & 21 & $1.6 \%$ & 44 & Mexico & 5 & $0.4 \%$ \\
\hline 15 & Viet Nam & 20 & $1.6 \%$ & 45 & Peru & 5 & $0.4 \%$ \\
\hline 16 & Ireland & 19 & $1.5 \%$ & 46 & Wallis and Futuna & 5 & $0.4 \%$ \\
\hline 17 & Taiwan & 18 & $1.4 \%$ & 47 & Colombia & 4 & $0.3 \%$ \\
\hline 18 & Rwanda & 17 & $1.3 \%$ & 48 & Georgia & 4 & $0.3 \%$ \\
\hline 19 & Kenya & 15 & $1.2 \%$ & 49 & Haiti & 4 & $0.3 \%$ \\
\hline 20 & Iran & 14 & $1.1 \%$ & 50 & Jersey & 4 & $0.3 \%$ \\
\hline 21 & Spain & 14 & $1.1 \%$ & 51 & Portugal & 4 & $0.3 \%$ \\
\hline 22 & Tanzania & 14 & $1.1 \%$ & 52 & Romania & 4 & $0.3 \%$ \\
\hline 23 & Zimbabwe & 14 & $1.1 \%$ & 53 & Singapore & 4 & $0.3 \%$ \\
\hline 24 & Malaysia & 13 & $1.0 \%$ & 54 & Burkina Faso & 3 & $0.2 \%$ \\
\hline 25 & Cameroon & 12 & $0.9 \%$ & 55 & Democratic Republic of the Congo & 3 & $0.2 \%$ \\
\hline 26 & Italy & 12 & $0.9 \%$ & 56 & Republic of the Congo & 3 & $0.2 \%$ \\
\hline 27 & France & 11 & $0.9 \%$ & 57 & Finland & 3 & $0.2 \%$ \\
\hline 28 & Botswana & 9 & $0.7 \%$ & 58 & Guinea & 3 & $0.2 \%$ \\
\hline 29 & Indonesia & 9 & $0.7 \%$ & 59 & Lebanon & 3 & $0.2 \%$ \\
\hline 30 & Puerto Rico & 8 & $0.6 \%$ & 60 & Mali & 3 & $0.2 \%$ \\
\hline
\end{tabular}

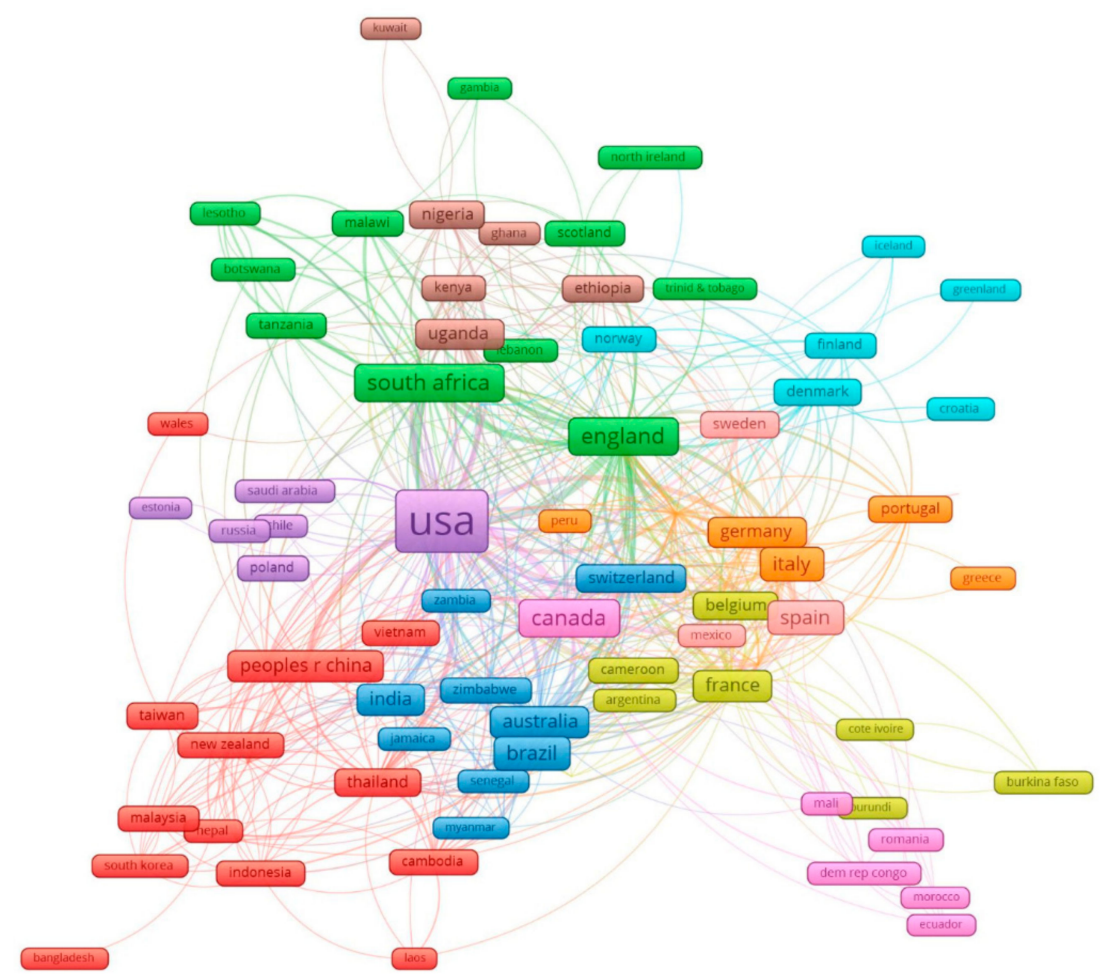

Figure 1. The network of 102 countries having international co-authorships in quality of life research in HIV/AIDS. 
Figure 2 describes the core components of the keywords with the most common groups of terms. There were four major clusters that emerged from 205 most frequent co-occurrence keywords with a minimum frequency of 20 times. Three major clusters (red, blue, and green) indicate three topics of quality of life.

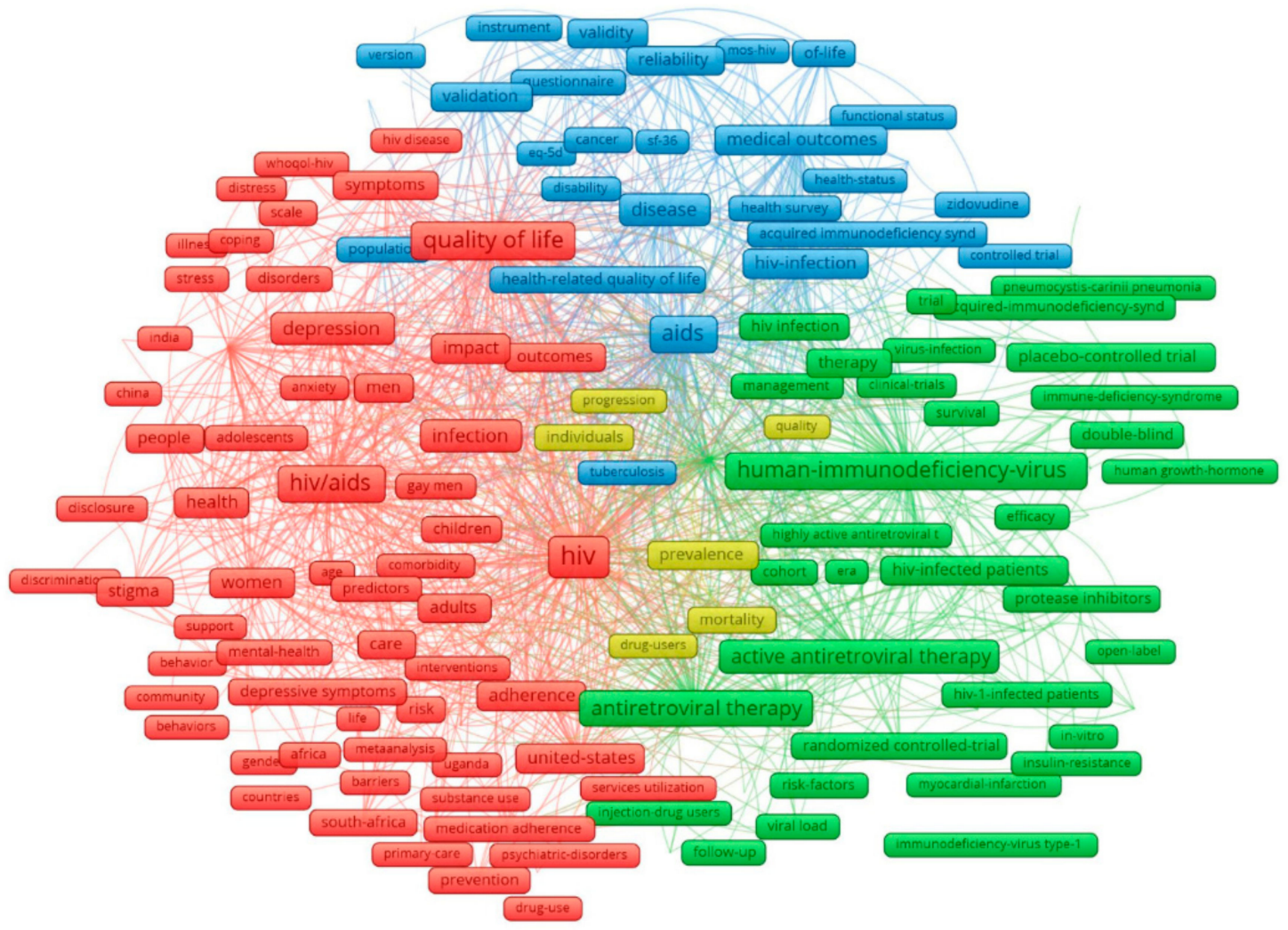

Figure 2. The most common author keywords. Note: the principal components of the data structure were visualized regarding the colors of the nodes; the node size was identified by the keywords' occurrences; the closer the nodes are, the stronger the association between two keywords are.

Cluster 1 (red) covers mental health, social, and associated factors. It includes psychological disorders (depression, anxiety, stress); social behavior (stigma, discrimination); specific HIV groups (such as gay, children, women, and men), and regions (India, South Africa, Uganda). Cluster 2 (blue) presents physical health-related aspects: treatment, outcome, mortality, and disability. Cluster 3 (green) indicates ART adherence studies: study design and laboratory results.

The top 50 emerging research domains have been discovered from the content analysis of abstracts using exploratory factor analysis (Table 3). Mental health (62.6\% of papers containing mental health-related keywords) appears to receive more attention from researchers compared to other health problems (e.g., chronic conditions $23.4 \%$, or cost-effectiveness $37.5 \%$ ). Other major domains cover coping strategies and social support. Nearly half of the articles have keywords related to the randomized and controlled trial. Meanwhile, the keywords concern comorbidities account for less than $10 \%$.

Figure 3 illustrates the similarity between QOL and the top 50 co-occurrence terms. In particular, physical, social, and health were the most common terms that co-occurred with QOL in all abstracts. The term related to women was more common than that of men in the literature. Antiretroviral, treatment, and infection were also co-occurrence terms with a high frequency of appearance. 
Proximity plot

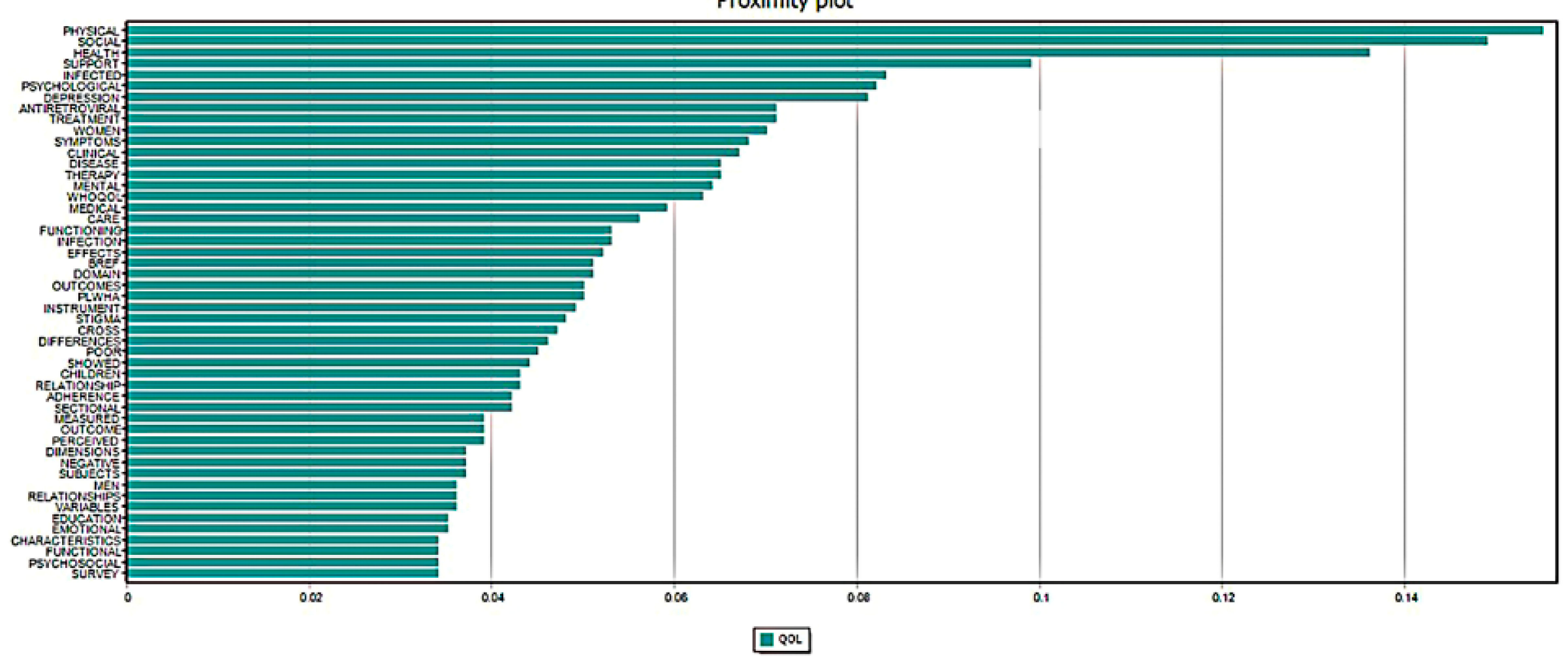

Figure 3. Proximity Plots of "quality of life" with the top 50 most frequent concurrence terms in abstracts. 
Table 3. Top 50 research domains emerged from exploratory factor analysis of all abstracts' contents.

\begin{tabular}{|c|c|c|c|c|}
\hline Name & Keywords & Eigen Value & FREQ & $\%$ Cases \\
\hline Mental health summary & $\begin{array}{l}\text { Medical Outcomes Study (MOS); summary; } \\
\text { mental; survey; physical; scores; medical; score; } \\
\text { health related quality of life (HRQOL); } \\
\text { outcomes; short form (SF) }\end{array}$ & 26.1 & 4123 & $62.60 \%$ \\
\hline Criteria; controlled trials & $\begin{array}{l}\text { Criteria; trials; objectives; controlled; main; } \\
\text { evidence; performed; review; evaluate }\end{array}$ & 1.9 & 2357 & $48.90 \%$ \\
\hline $\begin{array}{l}\text { The World Health Organization } \\
\text { Quality of Life brief } \\
\text { (WHOQOL-BREF); Domain }\end{array}$ & $\begin{array}{l}\text { WHOQOL; BREF; Domain; domains; world; } \\
\text { version; QOL; psychological; social }\end{array}$ & 3.3 & 2335 & $44.20 \%$ \\
\hline Randomized; Controlled trial & $\begin{array}{l}\text { Randomized; trial; placebo; controlled; weeks; } \\
\text { week; groups; primary; intervention }\end{array}$ & 7.2 & 2312 & $39.30 \%$ \\
\hline Cost-effectiveness; costs & $\begin{array}{l}\text { Cost; costs; effectiveness; effective; economic; } \\
\text { model; year }\end{array}$ & 1.9 & 1643 & $37.50 \%$ \\
\hline Coping strategies; social support & Coping; strategies; support; social & 1.3 & 1522 & $37.10 \%$ \\
\hline Depressive; anxiety and depression & $\begin{array}{l}\text { Depressive; depression; symptoms; anxiety; } \\
\text { psychiatric; psychological }\end{array}$ & 2.7 & 1722 & $36.10 \%$ \\
\hline Reliability and validity; item scale & $\begin{array}{l}\text { Validity; reliability; item; items; instrument; } \\
\text { factor; scales; measure; good; scale }\end{array}$ & 2.2 & 1923 & $36.10 \%$ \\
\hline Care access & Access; services; care & 1.3 & 1220 & $33.40 \%$ \\
\hline Role functioning & Role; function; cognitive; functioning & 1.5 & 1025 & $27.30 \%$ \\
\hline Viral load; count & Load; viral; count; counts; cells & 1.8 & 1384 & $27.00 \%$ \\
\hline Literature; review & Literature; review; evidence & 5 & 919 & $24.10 \%$ \\
\hline Sex; men and women & Sexual; men; sex; women & 1.8 & 1002 & $23.90 \%$ \\
\hline Chronic conditions & Conditions; chronic; diseases & 1.6 & 840 & $23.40 \%$ \\
\hline Stigma; disclosure & Stigma; disclosure; perceived; negative & 3.7 & 837 & $23.20 \%$ \\
\hline Cross-sectional & Sectional; cross; prevalence & 2.5 & 1128 & $23.00 \%$ \\
\hline Side effects & Side; effects & 1.5 & 815 & $22.80 \%$ \\
\hline Follow-up period & Period; follow; month; year & 2.3 & 852 & $22.50 \%$ \\
\hline Body mass; fat loss & $\begin{array}{l}\text { Mass; body; fat; weight; kg; loss; nutritional; } \\
\text { exercise; testosterone; index }\end{array}$ & 3.3 & 1169 & $21.40 \%$ \\
\hline Drug users & Users; methadone; drug; substance & 2.3 & 766 & $21.00 \%$ \\
\hline Outcome measures & Outcome; measures & 1.3 & 718 & $20.60 \%$ \\
\hline Control & Controls; control; intervention & 1.7 & 712 & $20.10 \%$ \\
\hline Anti; development & Anti; development; resistance; therapeutic & 1.2 & 712 & $19.70 \%$ \\
\hline Palliative; cancer pain & Palliative; cancer; advanced; pain & 1.9 & 620 & $18.20 \%$ \\
\hline Adherence to medication & Medication; adherence & 1.6 & 639 & $18.10 \%$ \\
\hline Developed countries & Countries; developed; settings & 1.2 & 600 & $18.00 \%$ \\
\hline Screening; early & Screening; early; settings & 1.2 & 500 & $15.50 \%$ \\
\hline Combination & Combination; response & 1.3 & 416 & $13.50 \%$ \\
\hline Demographic & Demographic; characteristics & 1.5 & 456 & $13.40 \%$ \\
\hline Children & Children; adoslescents; caregivers; family & 1.7 & 499 & $13.30 \%$ \\
\hline EuroQOL (EQ); HRQOL demension & EQ; HRQOL; Dimensions & 1.6 & 445 & $13.30 \%$ \\
\hline Reduction & Reduction; improvement & 1.4 & 407 & $13.10 \%$ \\
\hline Morbidity and mortality & Mortality; morbidity & 1.7 & 497 & $12.60 \%$ \\
\hline $\begin{array}{l}\text { Inhibitor; protease inhibitor (PI) } \\
\text { regimens }\end{array}$ & Inhibitor; PI; regimen; regimens & 3.1 & 498 & $12.20 \%$ \\
\hline Death & Death; hospital & 1.3 & 357 & $12.00 \%$ \\
\hline Emotional & Emotional; functional & 1.3 & 358 & $11.80 \%$ \\
\hline Exercise & Exercise; activity; week & 1.3 & 374 & $11.70 \%$ \\
\hline
\end{tabular}


Table 3. Cont.

\begin{tabular}{|c|c|c|c|c|}
\hline Name & Keywords & Eigen Value & FREQ & $\%$ Cases \\
\hline Moderate to severe & Severe; moderate; haemophilia & 1.5 & 390 & $11.70 \%$ \\
\hline Long-term & Term; long & 2.1 & 522 & $11.20 \%$ \\
\hline Adverse effect & Events; adverse & 1.4 & 426 & $11.20 \%$ \\
\hline Cytomegalovirus (CMV); Prophylaxis & CMV; prophylaxis; infections & 1.4 & 348 & $10.80 \%$ \\
\hline South Africa & South; Africa & 2 & 344 & $8.60 \%$ \\
\hline Food & $\begin{array}{l}\text { Food; people living with HIV (PLHIV); } \\
\text { nutritional }\end{array}$ & 1.3 & 225 & $6.90 \%$ \\
\hline Facial & Facial; satisfaction & 1.3 & 177 & $5.90 \%$ \\
\hline Hepatitis & Hepatitis; hepatitis C virus (HCV) & 1.9 & 215 & $5.60 \%$ \\
\hline Sleep & Sleep; fatigue & 1.4 & 155 & $4.80 \%$ \\
\hline Failure & Failure & 1.4 & 120 & $4.30 \%$ \\
\hline Anemia & Anemia & 1.4 & 49 & $1.70 \%$ \\
\hline Diarrhea & Diarrhea & 1.5 & 44 & $1.60 \%$ \\
\hline Tuberculosis (TB) & $\mathrm{TB}$ & 1.4 & 38 & $1.40 \%$ \\
\hline
\end{tabular}

\section{Discussion}

By analyzing the volume and abstract contents of global publications on the QOL of PLWHA during 1996-2017, our research captured and visualized the level of attention, current research trends, and the global networking of researches. The results show rather extensive coverage of topics in the existing literature, ranging from physical-related aspects to mental health, from issues concerning clinical trials to social support. Nonetheless, the current bibliography shows the lack of socio-cultural factors involved in the development and measurement of QOL.

Our study reports an increase in the number of papers using QOL as an important instrument for evaluating HIV/AIDS interventions since 1996, when highly active antiretroviral therapy (HAART) was first introduced [6]. This result is in line with a study conducted by Eltony et al., which confirmed an increasing trend in the volume of publications on QOL of PLWHA [35]. On the other hand, our findings draw a troubling picture regarding the degree of inequality in contributions and collaborative partnerships across settings. While most HIV incidence is located in LMICs, for instance, nearly $70 \%$ of individuals infected with HIV live in Sub-Saharan Africa [36], the highest amount of relevant studies belonged to high-income countries. It is widely acknowledged that the combination of low socioeconomic conditions and limited access to health services result in increasing HIV prevalence in sub-Saharan Africa, the Caribbean, and Central Asia [37]. Therefore, these countries may be more focused on the prevention of HIV transmission rather than investing interventions to improve mental health or social situation, for instance, to reduce stigma against HIV patients when accessing general health facilities. The reduction in global funds for HIV-the major source of financing for HIV/AIDS management in LMICs - would also lead to a lack of funding for the crucial activities of collecting empirical data, planning essential investigations, and HIV/AIDS management strategies [38]. Meanwhile, cross-regional collaborations, and especially research partnerships between high-income countries and their low-middle-income counterparts, have been found to still be rather limited (Figure 1). These findings call for more collaboration efforts between developed and developing nations, in which support both in terms of finance and knowledge/ technology should be transferred from advanced to disadvantaged regions. In addition, further research in favor of economic evaluation should be conducted to identify the appropriate interventions in the context of limited funding for HIV/AIDS management.

Knowing the association between the QOL of PLWHA and the effectiveness of HIV programs, QOL has been used as a criteria in assessing HIV/AIDS prevention programs, clinical treatment, and harm reduction strategies [39-41]. This is reflected in the finding of our study, as terms relating to QOL measurements like MOS-HIV, EQ-5D, SF-36, and WHOQOL-HIV are found to frequently 
co-occur with QOL in analyzed publications (Figure 2), while the EFA of abstract content identifies QOL measurements to be an emerging research domain (Table 3). EQ-5D and SF-36 have been broadly used thanks to their ability to be adopted for economic analyses. Meanwhile, MOS-HIV and WHOQOL-HIV have been developed and validated as QOL measurements specifically for the HIV/AIDS-infected population [42-46].

Even with the advancement of health services as well as the high ART coverage, the HIV/AIDS programs remain complex, contextual, and are often referred to as complicated because appropriate recommendations vary according to subpopulation and epidemiological context [23]. Previous studies have reported that in LMIC, a combination of factors, instead only one or two major ones, have major impacts on optimal adherence and rates of virological suppression when a patient is lost to follow-up [23]. The combined language and ethnicity profile of a country has been found to significantly influence culturally sensitive healthcare services-those at risk of HIV infection may face delayed treatment initiation and access to prevention services in regions where stigma against infectious diseases is common, for instance [47]. Some of the most HIV/AIDS-ridden nations in North-Central Africa, such as Cameroon, Nigeria, and the Democratic Republic of the Congo, have been found to also be the most culturally diverse countries [48]. The absence of culture-related terms like language, belief and religion in the keywords and abstract content of our analyzed publications suggest a gap in the research concerning the QoL of PLWHA. Further studies thus may consider assessing the role of cultural factors on QoL of PLWHA, as well as the impacts of diverse beliefs, for instance, on the effectiveness of the programs initiated to improve the QoL of those infected with HIV. Similarly, those involved in developing HIV/AIDS management programs, including policy-makers and non-governmental organizations, should take into account the impact of cultural factors.

The analysis of a principal component of terms in titles and abstracts reveals that QOL tends to co-occur with terms relating to mental disorders and high-risk populations, including adolescents, children, women, and gay. Disclosure, discrimination, and stigma have also been found to appear together with the aforementioned terms, along with keywords like barriers and primary care (Figure 2). This finding suggests that topics on the mental health consequences of HIV infection and its treatments, barriers to treatment due to stigmatization and social-related issues like reluctance to disclosure have been covered in the existing literature. The focus on single domains of $Q O L$, such as physical $[14,49,50]$, psychological $[49,51-53]$, social $[50,52-54]$, and environmental $[55,56]$ can be said to be common in research concerning QOL among PLWHA. However, given the complex, multi-dimensional nature of the QOL construct, the lack of contextualized factors (sociological perspective, culture, religion for instance) in the titles and abstracts of published papers, as our results reveal, can undermine the power and scope of impact of QOL on PLWHA and the effectiveness of treatments. Therefore, further studies are encouraged to address more contextualized factors and consider adopting multiple QOL measures when attempting to evaluate the association and influence of QOL on PLWHA.

Despite the positive findings of the study, several limitations should be mentioned. As our search strategy was conducted via Web of Science Core Collection solely and only English reviews and articles were included, despite the extensive coverage of WoS and the dominance of English publications, there is a chance that relevant publications not recorded in such a database and/or in other languages would be missed. Our decision to use only the term "quality of life" when conducting a publication search would also filter out possibly related papers where variations of the construct such as "satisfaction with life", "well-being"; "satisfaction" or "value of life" were used instead. Thus, further researches are strongly encouraged to consider investigating deviations of "quality of life" both as a term and a concept, especially research with a sociological focus. In addition, future studies may also be conducted in the form of systematic reviews and meta-analyses, for instance, on how QOL can or has been used as a measurement for assessing the effectiveness of HIV/AIDS treatments or interventions. 


\section{Conclusions}

Using bibliometrics analysis, we illustrate the development and current global trends of research on the QOL of PLWHA. Meanwhile, the results of the text mining techniques adopted provide a picture of current emerging research trends and topics and highlight research gaps. Despite a rather comprehensive coverage of topics relating to QOL in PLWHA, there has evidently been a lack of studies focusing on socio-cultural factors and their impacts on the QOL of those that are HIV-infected. Further studies should consider investigating the role of socio-cultural factors, especially where long-term treatment is involved. Policy-level decisions are recommended to be made based on the consideration of cultural factors, while collaborations between developed and developing nations, in particular with HIV/AIDS-ridden countries, are strongly recommended.

Author Contributions: Conceptualization, G.T.V., C.L.H., H.T.P., G.H.H. and R.C.M.H.; Data curation, B.J.H., H.T.P. and C.A.L.; Formal analysis, B.X.T., C.L.H., B.J.H. and H.T.P.; Funding acquisition, C.S.H.H. and G.H.H.; Investigation, B.X.T., B.J.H. and C.A.L.; Methodology, B.X.T., C.L.H., C.S.H.H. and G.H.H.; Project administration, G.T.V. and R.C.M.H.; Software, C.A.L. and G.H.H.; Supervision, G.T.V. and R.C.M.H.; Validation, C.S.H.H. and R.C.M.H.; Visualization, C.S.H.H.; Writing-original draft, G.T.V.; Writing—review and editing, G.T.V., B.X.T., C.L.H., B.J.H., H.T.P., C.A.L., C.S.H.H., G.H.H. and R.C.M.H. All authors have read and agreed to the published version of the manuscript.

Funding: This research received no external funding

Acknowledgments: Not applicable.

Conflicts of Interest: The authors declare no conflict of interest.

\section{Appendix A}

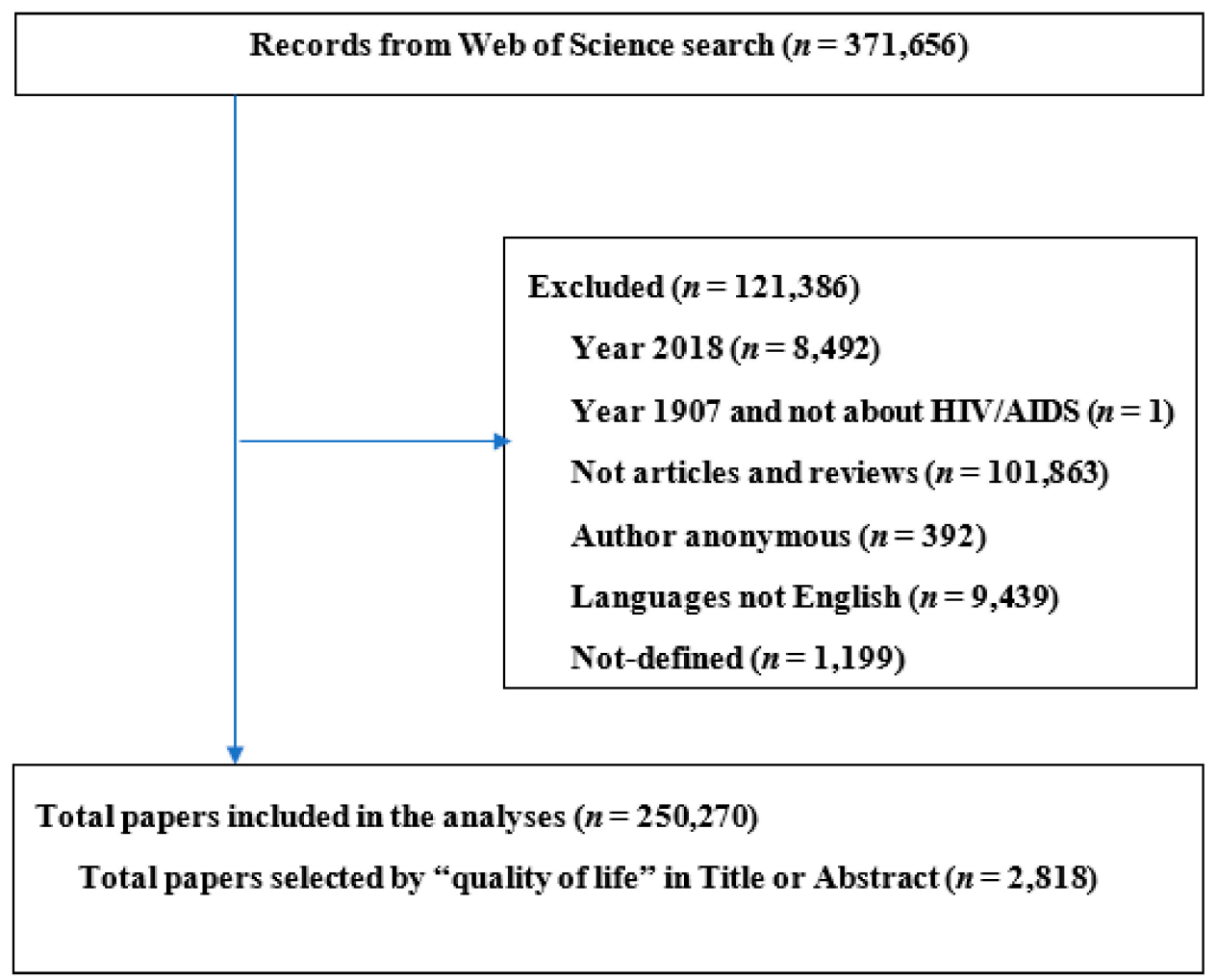

Figure A1. Selection of papers. The searching and paper selection process identified 250,270 related to HIV/AIDS. Among those, 2818 papers included the terms "quality of life". 
Table A1. Summary of the techniques and methods.

\begin{tabular}{|c|c|c|c|}
\hline $\begin{array}{c}\text { Type of } \\
\text { Data }\end{array}$ & $\begin{array}{c}\text { Unit of } \\
\text { Analysis }\end{array}$ & $\begin{array}{l}\text { Analytical } \\
\text { Methods }\end{array}$ & Presentations of Results \\
\hline $\begin{array}{l}\text { Abstracts } \\
\text { Keywords }\end{array}$ & Words & $\begin{array}{l}\text { Frequency of } \\
\text { co-occurrence }\end{array}$ & $\begin{array}{l}\text { 1. The number of articles by countries mentioned in the abstract } \\
\text { 2. Networks of co-occurrence authors' keywords } \\
\text { 3. Networks of countries by sharing co-authorships data }\end{array}$ \\
\hline Abstracts & $\begin{array}{c}\text { WoS research } \\
\text { domains }\end{array}$ & $\begin{array}{c}\text { Exploratory } \\
\text { factor analysis }\end{array}$ & 1. Top 50 research domains \\
\hline Abstracts & Words & $\begin{array}{c}\text { Jaccard's } \\
\text { similarity index }\end{array}$ & 1. Top 50 most frequent co-occurrence terms \\
\hline
\end{tabular}

\section{References}

1. Fauci, A.S. The AIDS epidemic-considerations for the 21st century. N. Engl. J. Med. 1999, 341, $1046-1050$. [CrossRef]

2. World Health Organization. Data on the size of the HIV/AIDS epidemic. Available online: http://apps.who. int/gho/data/view.main.22100WHO?lang=en (accessed on 26 January 2019).

3. GBD 2015 HIV Collaborators. Estimates of Global, Regional, and National Incidence, Prevalence, and Mortality of HIV, 1980-2015: The Global Burden of Disease Study 2015. Lancet HIV 2016, 3, e361-e387. [CrossRef]

4. UNAIDS. Global HIV \& AIDS statistics-2018 fact sheet. Available online: Aidsinfo.unaids.org (accessed on 12 December 2019).

5. Dennison, C.R. The role of patient-reported outcomes in evaluating the quality of oncology care. Am. J. Manag. Care 2002, 8, S580-S586.

6. Hudelson, C.; Cluver, L. Factors associated with adherence to antiretroviral therapy among adolescents living with HIV/AIDS in low- and middle-income countries: A systematic review. AIDS Care 2015, 27, 805-816. [CrossRef] [PubMed]

7. Safren, S.A.; Hendriksen, E.S.; Smeaton, L.; Celentano, D.D.; Hosseinipour, M.C.; Barnett, R.; Guanira, J.; Flanigan, T.; Kumarasamy, N.; Klingman, K.; et al. Quality of life among individuals with HIV starting antiretroviral therapy in diverse resource-limited areas of the world. AIDS Behav. 2012, 16, 266-277. [CrossRef] [PubMed]

8. Nojomi, M.; Anbary, K.; Ranjbar, M. Health-related quality of life in patients with HIV/AIDS. Arch. Iran. Med. 2008, 11, 608-612.

9. Pereira, M.; Canavarro, M.C. Gender and age differences in quality of life and the impact of psychopathological symptoms among HIV-infected patients. AIDS Behav. 2011, 15, 1857-1869. [CrossRef]

10. Wu, A.W.; Mathews, W.C.; Brysk, L.T.; Atkinson, J.H.; Grant, I.; Abramson, I.; Kennedy, C.J.; McCutchan, J.A.; Spector, S.A.; Richman, D.D. Quality of life in a placebo-controlled trial of zidovudine in patients with AIDS and AIDS-related complex. J. Acquir. Immune Defic. Syndr. 1990, 3, 683-690.

11. Freedberg, K.A.; Losina, E.; Weinstein, M.C.; Paltiel, A.D.; Cohen, C.J.; Seage, G.R.; Craven, D.E.; Zhang, H.; Kimmel, A.D.; Goldie, S.J. The cost effectiveness of combination antiretroviral therapy for HIV disease. $N$. Engl. J. Med. 2001, 344, 824-831. [CrossRef]

12. Cooper, V.; Clatworthy, J.; Harding, R.; Whetham, J.; Emerge, C. Measuring quality of life among people living with HIV: A systematic review of reviews. Health Qual. Life Outcomes 2017, 15, 220. [CrossRef]

13. Ragsdale, D.; Morrow, J.R.J.N.R. Quality of life as a function of HIV classification. Nurs. Res. 1990, 39, 355-359. [CrossRef] [PubMed]

14. Miners, A.; Phillips, A.; Kreif, N.; Rodger, A.; Speakman, A.; Fisher, M.; Anderson, J.; Collins, S.; Hart, G.; Sherr, L.J.T.1.H. Health-related quality-of-life of people with HIV in the era of combination antiretroviral treatment: A cross-sectional comparison with the general population. Lancet HIV 2014, 1, e32-e40. [CrossRef]

15. Hasan, S.S.; Keong, S.C.; Choong, C.L.; Ahmed, S.I.; Ching, T.W.; Anwar, M.; Ahmadi, K.; Babar, M.G. Patient-reported adverse drug reactions and drug-drug interactions: A cross-sectional study on Malaysian HIV/AIDS patients. Med. Princ. Pract. 2011, 20, 265-270. [CrossRef] [PubMed]

16. Boyer, S.; Protopopescu, C.; Marcellin, F.; Carrieri, M.P.; Koulla-Shiro, S.; Moatti, J.P.; Spire, B.; Group, E.S. Performance of HIV care decentralization from the patient's perspective: Health-related quality of life and perceived quality of services in Cameroon. Health Policy Plan. 2012, 27, 301-315. [CrossRef] [PubMed] 
17. Liu, C.; Johnson, L.; Ostrow, D.; Silvestre, A.; Visscher, B.; Jacobson, L.P. Predictors for lower quality of life in the HAART era among HIV-infected men. J. Acquir. Immune Defic. Syndr. 2006, 42, 470-477. [CrossRef]

18. Drewes, J.; Gusy, B.; Ruden, U. More than 20 years of research into the quality of life of people with HIV and AIDS-a descriptive review of study characteristics and methodological approaches of published empirical studies. J. Int. Assoc. Provid. AIDS Care 2013, 12, 18-22. [CrossRef]

19. Mafirakureva, N.; Dzingirai, B.; Postma, M.J.; van Hulst, M.; Khoza, S. Health-related quality of life in HIV/AIDS patients on antiretroviral therapy at a tertiary care facility in Zimbabwe. AIDS Care 2016, 28, 904-912. [CrossRef]

20. Aranda-Naranjo, B. Quality of life in the HIV-positive patient: Implications and consequences. J. Assoc. Nurses AIDS Care 2004, 15, 20S-27S. [CrossRef]

21. Davis, S. Clinical sequelae affecting quality of life in the HIV-infected patient. J. Assoc. Nurses AIDS Care 2004, 15, 28S-33S. [CrossRef]

22. Tran, B.X.; Hwang, J.; Nguyen, L.H.; Nguyen, A.T.; Latkin, N.R.; Tran, N.K.; Minh Thuc, V.T.; Nguyen, H.L.; Phan, H.T.; Le, H.T.; et al. Impact of Socioeconomic Inequality on Access, Adherence, and Outcomes of Antiretroviral Treatment Services for People Living with HIV/AIDS in Vietnam. PLoS ONE 2016, 11, e0168687. [CrossRef]

23. Jin, Y.; Liu, Z.; Wang, X.; Liu, H.; Ding, G.; Su, Y.; Zhu, L.; Wang, N. A systematic review of cohort studies of the quality of life in HIV/AIDS patients after antiretroviral therapy. Int. J. STD AIDS 2014, 25, 771-777. [CrossRef] [PubMed]

24. Gakhar, H.; Kamali, A.; Holodniy, M. Health-related quality of life assessment after antiretroviral therapy: A review of the literature. Drugs 2013, 73, 651-672. [CrossRef] [PubMed]

25. Wu, A.W.; Hanson, K.A.; Harding, G.; Haider, S.; Tawadrous, M.; Khachatryan, A.; Pashos, C.L.; Simpson, K.N. Responsiveness of the MOS-HIV and EQ-5D in HIV-infected adults receiving antiretroviral therapies. Health Qual. Life Outcomes 2013, 11, 42. [CrossRef] [PubMed]

26. Jeavons, S.; Greenwood, K.M.; Horne, D.J. Accident cognitions and subsequent psychological trauma. J. Trauma. Stress 2000, 13, 359-365. [CrossRef]

27. Tran, B.X.; Vu, G.T.; Ha, G.H.; Vuong, Q.H.; Ho, M.T.; Vuong, T.T.; La, V.P.; Ho, M.T.; Nghiem, K.P.; Nguyen, H.L.T.; et al. Global Evolution of Research in Artificial Intelligence in Health and Medicine: A Bibliometric Study. J. Clin. Med. 2019, 8, 360. [CrossRef]

28. Tran, B.X.; Moir, M.; Latkin, C.A.; Hall, B.J.; Nguyen, C.T.; Ha, G.H.; Nguyen, N.B.; Ho, C.S.H.; Ho, R.C.M. Global research mapping of substance use disorder and treatment 1971-2017: Implications for priority setting. Subst. Abus. Treat. Prev. Policy 2019, 14, 21. [CrossRef]

29. Tran, B.X.; Ho, R.C.M.; Ho, C.S.H.; Latkin, C.A.; Phan, H.T.; Ha, G.H.; Vu, G.T.; Ying, J.; Zhang, M.W.B. Depression among Patients with HIV/AIDS: Research Development and Effective Interventions (GAPRESEARCH). Int. J. Environ. Res. Public Health 2019, 16, 1772. [CrossRef]

30. Tran, B.X.; Dang, K.A.; Le, H.T.; Ha, G.H.; Nguyen, L.H.; Nguyen, T.H.; Tran, T.H.; Latkin, C.A.; Ho, C.S.H.; Ho, R.C.M. Global Evolution of Obesity Research in Children and Youths: Setting Priorities for Interventions and Policies. Obes. Facts 2019, 12, 137-149. [CrossRef]

31. Hoang, C.L.; Ha, G.H.; Kiet, P.H.T.; Tran, B.X.; Latkin, C.A.; Ho, C.S.H.; Ho, R.C.M. Global Mapping of Interventions to Improve Quality of Life of Patients with Alzheimer's Disease during 1990-2018. Dement. Geriatr. Cogn. Disord. 2020, 1-3. [CrossRef]

32. Analytics, C. Web of Science platform: Web of Science: Summary of Coverage. Available online: https: //clarivate.libguides.com/webofscienceplatform/coverage (accessed on 18 March 2020).

33. Katz, D.I.; Cohen, S.I.; Alexander, M.P. Mild traumatic brain injury. Handb. Clin. Neurol. 2015, 127, $131-156$. [CrossRef]

34. Kessler, R.C.; Barker, P.R.; Colpe, L.J.; Epstein, J.F.; Gfroerer, J.C.; Hiripi, E.; Howes, M.J.; Normand, S.L.; Manderscheid, R.W.; Walters, E.E.; et al. Screening for serious mental illness in the general population. Arch. Gen. Psychiatry 2003, 60, 184-189. [CrossRef] [PubMed]

35. Diwakar, P. O16. 1 Quality of Life and HIV-A Bibliometric Analysis of Publication Trends between 1995 to 2013 ; BMJ Publishing Group Ltd.: London, UK, 2017.

36. Kharsany, A.B.; Karim, Q.A. HIV Infection and AIDS in Sub-Saharan Africa: Current Status, Challenges and Opportunities. Open AIDS J. 2016, 10, 34-48. [CrossRef] [PubMed] 
37. Shao, Y.; Williamson, C. The HIV-1 epidemic: Low- to middle-income countries. Cold Spring Harb. Perspect. Med. 2012, 2, a007187. [CrossRef] [PubMed]

38. UNAIDS. The Collapse of Global AIDS Funding; UNAIDS: Geneva, Switzerland, 2016.

39. Rueda, S.; Mitra, S.; Chen, S.; Gogolishvili, D.; Globerman, J.; Chambers, L.; Wilson, M.; Logie, C.H.; Shi, Q.; Morassaei, S.; et al. Examining the associations between HIV-related stigma and health outcomes in people living with HIV/AIDS: A series of meta-analyses. BMJ Open 2016, 6, e011453. [CrossRef] [PubMed]

40. Swindells, S.; Mohr, J.; Justis, J.C.; Berman, S.; Squier, C.; Wagener, M.M.; Singh, N. Quality of life in patients with human immunodeficiency virus infection: Impact of social support, coping style and hopelessness. Int. J. STD AIDS 1999, 10, 383-391. [CrossRef]

41. Pozniak, A. Quality of life in chronic HIV infection. Lancet HIV 2014, 1, e6-e7. [CrossRef]

42. Canavarro, M.C.; Pereira, M. Factor structure and psychometric properties of the European Portuguese version of a questionnaire to assess quality of life in HIV-infected adults: The WHOQOL-HIV-Bref. AIDS Care 2012, 24, 799-807. [CrossRef]

43. Pereira, M.; Martins, A.; Alves, S.; Canavarro, M.C. Assessing quality of life in middle-aged and older adults with HIV: Psychometric testing of the WHOQOL-HIV-Bref. Qual. Life Res. 2014, 23, 2473-2479. [CrossRef]

44. Hsiung, P.C.; Fang, C.T.; Wu, C.H.; Sheng, W.H.; Chen, S.C.; Wang, J.D.; Yao, G. Validation of the WHOQOL-HIV BREF among HIV-infected patients in Taiwan. AIDS Care 2011, 23, 1035-1042. [CrossRef]

45. Saddki, N.; Noor, M.M.; Norbanee, T.H.; Rusli, M.A.; Norzila, Z.; Zaharah, S.; Sarimah, A.; Norsarwany, M.; Asrenee, A.R.; Zarina, Z.A. Validity and reliability of the Malay version of WHOQOL-HIV BREF in patients with HIV infection. AIDS Care 2009, 21, 1271-1278. [CrossRef]

46. Tran, B.X. Quality of life outcomes of antiretroviral treatment for HIV/AIDS patients in Vietnam. PLoS ONE 2012, 7, e41062. [CrossRef] [PubMed]

47. Tucker, C.M.; Marsiske, M.; Rice, K.G.; Nielson, J.J.; Herman, K. Patient-centered culturally sensitive health care: Model testing and refinement. Health Psychol. 2011, 30, 342-350. [CrossRef] [PubMed]

48. Nota, S.P.; Bot, A.G.; Ring, D.; Kloen, P.J.I. Disability and depression after orthopaedic trauma. Injury 2015, 46, 207-212. [CrossRef]

49. Larios, S.E.; Davis, J.N.; Gallo, L.C.; Heinrich, J.; Talavera, G. Concerns about stigma, social support and quality of life in low-income HIV-positive Hispanics. Ethn. Dis. 2009, 19, 65-70. [PubMed]

50. Medeiros, R.; Medeiros, J.A.; Silva, T.; Andrade, R.D.; Medeiros, D.C.; Araujo, J.S.; Oliveira, A.M.G.; Costa, M.A.A.; Dantas, P.M.S. Quality of life, socioeconomic and clinical factors, and physical exercise in persons living with HIV/AIDS. Rev. Saude Publica 2017, 51, 66. [CrossRef] [PubMed]

51. Calvetti, P.Ü.; Giovelli, G.R.M.; Gauer, G.J.C.; Moraes, J.F.D.d. Psychosocial factors associated with adherence to treatment and quality of life in people living with HIV/AIDS in Brazil \%J Jornal Brasileiro de Psiquiatria. J. Brasileiro De Psiquiatria 2014, 63, 8-15. [CrossRef]

52. Ruiz Perez, I.; Rodriguez Bano, J.; Lopez Ruz, M.A.; del Arco Jimenez, A.; Causse Prados, M.; Pasquau Liano, J.; Martin Rico, P.; de la Torre Lima, J.; Prada Pardal, J.L.; Lopez Gomez, M.; et al. Health-related quality of life of patients with HIV: Impact of sociodemographic, clinical and psychosocial factors. Qual. Life Res. 2005, 14, 1301-1310. [CrossRef]

53. Lutgendorf, S.; Antoni, M.H.; Schneiderman, N.; Fletcher, M.A. Psychosocial counseling to improve quality of life in HIV infection. Patient Educ. Couns. 1994, 24, 217-235. [CrossRef]

54. Bastardo, Y.M.; Kimberlin, C.L. Relationship between quality of life, social support and disease-related factors in HIV-infected persons in Venezuela. AIDS Care 2000, 12, 673-684. [CrossRef]

55. Sowell, R.L.; Seals, B.F.; Moneyham, L.; Demi, A.; Cohen, L.; Brake, S. Quality of life in HIV-infected women in the south-eastern United States. AIDS Care 1997, 9, 501-512. [CrossRef]

56. Bachmann, M.O.; Louwagie, G.; Fairall, L.R. Quality of life and financial measures in HIV/AIDS in Southern Africa; Springer: New York, NY, USA, 2010; pp. 3223-3243.

(C) 2020 by the authors. Licensee MDPI, Basel, Switzerland. This article is an open access article distributed under the terms and conditions of the Creative Commons Attribution (CC BY) license (http://creativecommons.org/licenses/by/4.0/). 